\title{
Bureaucratic Barriers to Evidence-based Tobacco Control Policy: A Tasmanian Case Study
}

\author{
Kathryn Barnsley ", Haydn Walters, Richard Wood-Baker \\ Centre of Research Excellence for Chronic Respiratory Disease and Lung Ageing, University of Tasmania, Australia
}

Copyright $@ 2015$ Horizon Research Publishing All rights reserved.

\begin{abstract}
The aim was to examine bureaucratic barriers to implementing strategies for tobacco control in Tasmania. We analysed documents provided by government agencies under Right to Information legislation; documents provided by non-government organisations (NGOs), newspaper reports, websites and Hansards relevant for the period 1997 to 2010. Responsible Tasmanian bureaucratic organisations have had a culture of avoiding responsibility for high smoking rates, their processes being excessively complex, under-resourced in expertise and funding for mass media campaigns, having poor accountability mechanisms, failed to adhere to international standards in dealings with the tobacco industry, failed to follow evidence-based public policy despite being aware of its existence, were distracted by immediate needs, experienced passive and active obstruction from other government agencies, and did not adequately inform the Parliament about measures which might reduce smoking rates. The operation and culture of the Tasmanian bureaucracy has been a significant barrier to evidence-based tobacco control public policy. This deficiency was not confined to the Department of Health and Human Services, but also included the Departments of Premier and Cabinet and Treasury. Major barriers to evidence-based tobacco control have existed within the bureaucratic systems in Tasmania in the period 1997 to 2010. They were excessively process-driven, complex structures, with lack of "evidence transfer", antipathetic in culture and had scant resources. Similar barriers exist in some other jurisdictions. All this served to undermine the effectiveness of public-health expert-driven action.
\end{abstract}

Keywords Bureaucracy, Tobacco Control, Public Policy, Smoking, Evidence Transfer,

\section{Introduction}

Despite significant international leadership in areas of tobacco control legislation, implementation of a comprehensive evidence-based tobacco control policy in Tasmania has been unsuccessful. Australian smoking rates are declining, but the 2011-12 ABS National Health Survey (NHS) showed Tasmanian adult smoking rate to be 20.6 per cent, significantly higher than the national rate of $16.1 \%$, and this had not fallen significantly since 2001. Of particular concern, 37 per cent to Tasmanian men aged 25-44 years were current smokers - nearly twice the national smoking rate for younger men. [1] Tasmania has significantly higher poverty and lower SES than other States, which influences smoking rates, [2] but from 1997 to 2010 measures known to be effective in reducing smoking rates in such populations were not implemented, or were substantially delayed.

Tasmania is an island state of Australia, located south of mainland Australia, west of New Zealand in a similar cool temperate latitude, with a population of around 500,000. It has a bicameral system of government, with two Houses of Parliament. In Australia most taxation is collected by the federal government and distributed to the states. State taxation revenue is therefore limited, and $60 \%$ of Tasmania's revenue is from grants [3]. Around $45 \%$ of Tasmania is in reserves, including national parks and world heritage areas. Tasmania is famous for its wild scenery, healthy climate and unique flora and fauna, including the endangered Tasmanian devil. The population is relatively homogenous and stable, with modest immigration and the majority of residents are of British descent. It provides an exceptional location for longitudinal population health research, and is engaged in several international research collaborations. A former Director of the Menzies Institute for Medical Research said in 2006, "Tasmania's stable population, excellent genealogical records and the generosity of the community make this state a unique and ideal place to conduct ground-breaking research on common and chronic health problems." [4] In February 2004 then Premier Jim Bacon retired from Parliament, due to lung cancer caused by smoking, and died soon afterwards. His shocked colleagues initiated further restrictions on smoking, and it was the first Australian state to introduce hotel and gaming premises smoking bans in 2006.

This paper examines some of the bureaucratic barriers to evidence-based tobacco control, particularly relating to the use of mass media anti-tobacco campaigns and cessation support services in Tasmania from 1997 to 2010. Tasmania 
initiated several international and Australian "firsts" in tobacco legislation reform, such as the removal of tobacco advertisements at point-of sale, [5] however several evidence based initiatives which required funding or resources were shelved, or substantially delayed. There is no detailed comparison with other states in this paper, nor are the roles of politicians, non-government organisations (NGOs) and the tobacco industry analysed.

\section{Methods}

\subsection{Design}

A qualitative data analysis of the role of the bureaucracy was conducted, using documentation obtained from various sources for 1997 to 2010 .

The theoretical framework used is that of Kingdon [6], with particular emphasis on agenda-setting, knowledge-transfer and organisational structures.

\subsection{Data Collection}

Documents relating to tobacco control were sought from: Health and Human Services (DHHS), Primary Industry Parks and Water (DPIPWE), Treasury and Finance (DOTAF), and Premier and Cabinet (DPAC). Some documents were provided by non-government organisations (NGOs).

\subsection{Data Analysis}

Digital documents were analysed and coded using QSR International Nvivo. Other documents were sorted and analysed manually. Grey literature searches included published government reports, newspaper reports, government websites and tobacco industry document websites [7]. Parliamentary Hansards [8] relevant to the period were extracted and analysed.

\section{Results}

Table 1. Results and Discussion

\begin{tabular}{|c|c|}
\hline \multicolumn{2}{|c|}{ Results and Discussion } \\
\hline $\begin{array}{c}\text { Structural Barriers and } \\
\text { accountability }\end{array}$ & $\begin{array}{c}\text { Responsibility split between the Alcohol and Drug Service (ADS) and Public and Environmental Health } \\
\text { (PEH), too many committees. Confused accountability. }\end{array}$ \\
\hline $\begin{array}{c}\text { Priorities and skills in the Alcohol } \\
\text { and Drug Service (ADS) }\end{array}$ & $\begin{array}{c}\text { No statewide expertise in clinical delivery of cessation services. No interest in tobacco control. Too many } \\
\text { layers of management. Many staff were smokers. Decrease in services to the main hospital. }\end{array}$ \\
\hline Lack of "Evidence Transfer" & $\begin{array}{c}\text { Reports to Parliament did not mention the importance of mass media campaigns. Key senior officers did not } \\
\text { believe that media campaigns were effective. }\end{array}$ \\
\hline Complex processes & Complex and slow committee systems. Excessive internal iterative circular "consultation". \\
\hline Cultural Barriers & $\begin{array}{c}\text { "Primacy of rescue" dominated drug policies and committees; alcohol and illicits elicited priority action. } \\
\text { "Siloed" Health agency received no support, and some active obstruction, from other key agencies. } \\
\text { Indifference from other sections of health agency, such as mental health services. }\end{array}$ \\
\hline Influence of the tobacco industry & $\begin{array}{c}\text { Insufficient distancing from the tobacco industry, particularly from Departments other than health. Worked } \\
\text { with "front" organisations. Lack of transparency -naively considered more a "third world" problem, not here. }\end{array}$ \\
\hline Resource constraints & $\begin{array}{c}\text { Difficulties in obtaining funds for tobacco control, because of resource "silo" effect. Tasmania has limited } \\
\text { resources, due to a small tax base, and reliance on the federal government for its revenue. }\end{array}$ \\
\hline Evaluation delays & $\begin{array}{r}\text { The principal service delivery arm, Quit Tasmania, was not evaluated from its establishment in 1995 until } \\
\text { 2009. Many problems were found, but not implemented for another two years. }\end{array}$ \\
\hline
\end{tabular}

There were 2192 hits for the word "tobacco" in 289 approximately 123 pages, and approximately 35,000 pages were examined. Relevant records were copied and coded into NVivo using Microsoft Word. Older newspaper reports were obtained from microfiche records at the State Library of Tasmania, via a card index system using the keywords 'tobacco' and 'smoking'. More recent newspaper reports were obtained from online Newsbank by searching the keyword 'tobacco' and 'smoking' through Linc of the State Library of Tasmania. Major bureaucratic barriers to evidence-based tobacco control policy were identified. The following sections discuss these themes.

\section{Discussion}

\subsection{The Policy Environment is CRUCIal to Effective Tobacco Control}

Leading international writers on tobacco control policy and governance, Studlar, Cairney and Mamudu recognize that the "...strength of tobacco control may be linked to the power of the health department and the extent to which it takes the lead within government." [9] The role of government agencies is key to implementation of tobacco control policies, and any restrictions on the power and influence of the health agency can operate as a brake on reform, as it has in specific areas in Tasmania. Cairney and Mamudu also observed that in almost all countries some measures "....economic incentives and litigation - are less likely to be introduced than others" and that "implementation involves much more than generating evidence -based objectives and policy instruments". [10] It is not enough to have the evidence accessible and available, it has to be believed, and transferred to those who can implement policy. It is absolutely clear that even in a middle income jurisdiction "...the policy environment is as important as the policy instruments designed to eradicate tobacco use." [10] 


\subsection{Structural Barriers and Accountability}

The first identifiable barrier was the split between policy-making and service-delivery arms in government, i.e. the Public and Environmental Health Service (PEHS) on the one hand and the Alcohol and Drug Service (ADS) on the other. PEHS is responsible for tobacco regulation and enforcement, whereas ADS is responsible for cessation service delivery, but its focus has been on dealing with illicit drugs and alcohol. [11] At the same time statutory responsibility for smoking tobacco control was and continues to be vested in the role of Director of Public Health, under the Public Health Act 1997 but without practical executive policy authority in this domain. ADS controlled all drug policy, was the conduit to the health minister, and national ministerial and intergovernmental committees for any drug policy advice, including that on tobacco. However, there was a distinct lack of clarity regarding activities which are statutory requirements and those which are non-statutory. [12]

Processes have been sluggish and unwieldy. The Inter Agency Working Group on Drugs (IAWGD). [S1] comprising representatives of the Departments of Health and Human Services, Police, Education, Premier and Cabinet, Treasury, Justice, and the Alcohol, Tobacco and Other Drugs Council (ATODC), and provided advice to the national Ministerial Council on Drugs Strategy (MCDS) and the Inter-Governmental Committee on Drugs (IGCD). However, the MCDS and IGCD gave primary attention to illicit drugs, with little attention given to tobacco, and were slow and cumbersome. All Tasmanian representatives were from Police or Alcohol and Drug Service, not from PEHS, and had no tobacco interest. [S8,S9] The 2009-2010 IGCD Annual Report to the Ministerial Council on Drug Strategy concerning Tasmania contains about three times as many references to alcohol as tobacco. [13] McDonald, a key drug policy reviewer, said ,"In recent years the IGCD/MCDS advisory structures have been explicitly and intentionally structured to filter the information inputs, one result of which is that the research evidence receives less attention, in policy considerations, than it should.' [S2] McDonald said of Australian Drug Policy "'This pattern of resource allocation does not adequately reflect an evidence-informed policy orientation in that it largely fails to focus on the drug types that are the sources of the most harm (tobacco and alcohol rather than illicit drugs), and the sectors for which we have the strongest evidence of the cost-effectiveness of the available interventions." $[14,15]$ The committee system was a factor in the limitations of the complex web of public sector agencies given authority to deal with drugs issues, but with little focus on smoking.

\subsection{Priorities and Skills in the ADS}

Although responsible for clinical delivery of smoking cessation support, the ADS, had little expertise in tobacco control policy. In 2006 the Clinical Director of ADS resigned from the Department citing concerns about management and lack of funding, resulting in headlines in the Hobart Mercury newspaper and he was quoted as saying ".....there seemed to be layers of management for management's sake...."[16] The Tobacco Coalition was the principle Committee dealing with tobacco issues (see later) and reported in 2006, "Alcohol and Drug Services ...... would not be able to 'evaluate effectiveness, efficiency and accessibility of cessation services in clinical, community and regional areas'. [S3]

The Department of Health and Human Services commissioned a review of Tasmanian tobacco cessation services by Global Public Health, which found in 2007 that "Smoking cessation is not a priority in the Alcohol and Drug Services" and "The culture of smoking in mental health and alcohol and drug services limits smoking cessation interventions and addressing of smoking by staff". [S4] Documents consistently revealed that the lack of priority given to smoking cessation by the ADS became a barrier to reform and initiation of effective programs; one departmental document records that concerns were raised regarding" ...the decrease in cessation services provided by Alcohol and Drug Services particularly at the Royal Hobart Hospital." [S5]

As a result of the Review ADS obtained additional funding in the 2009 Budget and from that time the Department's major emphasis was on the provision of clinical smoking cessation services, but notably not on anti-smoking media campaigns, which are known to be highly effective, and recommended as a priority by the Review. [S6][17-23]

\subsection{Lack of "Evidence Transfer"}

The Director of Public Health is required by law to produce a report to Parliament every five years on the state of public health and reports were produced in 2003 and 2008. $(24,25)$ Both these reports dealt with the issue of smoking rates in Tasmania, but neither report mentioned the strategic importance of mass media educational campaigns.[24,25] In the 2008 report the Director said in his recommendations that "A further major priority for new investment must be the establishment of a robust smoking cessation program for Tasmania, in accordance with the recommendations made by the Department of Health and Human Services following a recent review of smoking cessation interventions in Tasmania."[25] This focus on clinical services ignored the fact that report had also recommended that effective community mass media campaigns be a priority. [S5] Significantly, the 2008 report listed the practical activities undertaken to reduce smoking rates, namely graphic health warnings at point of sale, increased prosecutions of sales to minors, extending smoke free areas to bars, prohibiting: split packets, the sale of fruit and confectionery flavoured cigarettes, smoking in cars with children present and reduction in the size of tobacco displays - but again did not list the most effective strategy (of mass media campaigns) as a priority, despite this having been a major recommendation 
of the review the Director was quoting. He rejected "...educational approaches or 'health messages' alone" and added that "The challenge now is to improve investment in smoking cessation support". [25] It was not until 2013 that the report promoted the need for mass media campaigns. [2] The Parliament was not advised until 2013, in the major report by the key statutory office holder on Tasmanian Public Health that mass media campaigns are important in tobacco control, in spite of overwhelming evidence of their effectiveness for decades. [2]

\subsection{Complex Processes}

The complex committee system in Tasmania stifled progress, as three separate committees specifically dealt with tobacco control and acted as a conduit to the Minister i.e. the Tobacco Coalition (TC), the Alcohol Tobacco and Other Drugs Steering Committee (ATODS) and the Inter-Agency Working Group on Drugs (IAWGD).

The lowest ranked and least influential tobacco control committee operating from 2004 within the DHHS was the TC, a stakeholder group of local DHHS and Education Department, the Commonwealth Health and Ageing (DOHA) and non-government organisation representatives. The TC was intended to "...enhance coordination and communication between government Departments and service providers". [S7] This strategy failed mainly because, after brief initial involvement, the state departments' representatives hardly ever attended the meetings. By 2009 the TC was buried under another layer of bureaucracy, with access to the Minister only through the ATODS, (a DHHS group including senior officers from Mental Health Services, Alcohol and Drug Service, PHES and a Service Development representative), then through the IAWGD. [S8]

The Inter-Agency Working Group on Drugs (IAWGD) was established in 2004 as a cross agency working group to coordinate the service delivery of drug-related initiatives, and to act as the principal advisory group for drugs-related policy in Tasmania. Tobacco control initiatives from the TC were filtered through this group whose membership comprised the Departments of Health, Police, Premier and Cabinet, Treasury, Infrastructure, Education, Justice, Local government, Alcohol Tobacco and Other Drugs Council and the Commonwealth. It was not until 2008 that a suggestion was made that the Director of Public Health be invited to the committee. Typically despite being responsible for all tobacco control since 1996, the Director had been excluded for four years from the "principal advisory group". [S9]

The 2006-2010 Tasmanian Tobacco Action Plan took six years to develop. Some of the confusion about the development of the plan can be seen in internal e-mails within the DHHS between the ADS and the PEHS in 2003. "I already forwarded the documents to X on 4 June 2003, but here they are again." and ".... whatever group had steered the process...I don 't know which group that was...", and "We have no idea of who has the final documents."[S10] The original national Plan was approved by the federal and state ministers in 1999, but a Tasmanian Plan did not arrive in the Ministers' office for approval until 2004 which was after the scheduled completion date of the original national plan. Even after the Plan was approved by the Minister it had to traverse more committees. A ministerial briefing indicated that , the document had to be forwarded ".... for final endorsement via the Inter-Agency Policy Coordination Committee to the Cabinet Social Policy Sub Committee" and "...once endorsed the Plan will be provided to the inter-governmental committee on Drugs (IGCD) and the Tobacco, Drug prevention and Youth Policy Section of the Commonwealth Department of Health and Ageing" and “...will also be provided to the healthy Lifestyles Interdepartmental Committee for noting" and "....is aligned with the Tasmania Together Healthy Lifestyle cluster group coordinated by the Population Health sub-division." [S11]

Similarly the Implementation Plan, Target 16, for the Tobacco Action Plan 2006-2010 took three years to reach the ATODS and the health minister (in 2009 - a few months prior to the expiry of the main plan) for final approval. [S12] However, these approval processes are mirrored the national drug strategy policy processes which have also been criticised for exceptional sluggishness. $[26,27]$ The plethora of Tasmanian preventive health strategic plans has been criticised by the Auditor General. [12] The US Food and Drug Administration regulation of tobacco products has also received similar criticism "...action is sometimes sacrificed to process". [28]

\subsection{Cultural Barriers}

Cultural barriers within the bureaucracy may be the prime reason for a lack of progress in tobacco control in Tasmania. Key lead agencies on the IAWGD, namely the Police and ADS deal with the "primacy of rescue", i.e. immediate and visible public alarm, in particular public alcohol abuse and illicit drug use. [29] Their focus is not on long term prevention.[S13] Police have opposed the Tobacco Coalition having any public advocacy role, because of perceived potential conflict of interest. "Following concerns raised by (the Police Representative) ... it was agreed that the Coalition would not make comment in the media or be used as a public advocacy group." [S14] As Mcginnis writes in his essay on evidence-based policy, strong evidence can thus lead to weak preventive action.[29] During 2009, mass media marketing for anti-smoking campaigns "fell off" the agenda. For example, the "Future Service Directions for ATOD", a five year plan from 2008/09 to 2012/13 mentions as the first initiative potential investment in media campaigns. However, in the subsequent 2009 project management reports to the Alcohol Tobacco and Other Drugs Steering Committee (ATODSC) this item had disappeared. Thus a potential key evidence based mechanism for reducing smoking rates in Tasmania, vanished from the agenda of the only committee which could make recommendations through the IAWGD to the health 
minister.[S15]

The second major cultural barrier has been the passive and active obstruction from agencies external to the DHHS. The fact that DHHS is the lead agency on tobacco control meant that it became, as described by Isett, "siloed" and consequently "elicit[ed] little aid in implementation from other agencies that may have a stake in the policy outcome". [30] Two central agencies, namely Department of Premier and Cabinet (DPAC) and Department of Treasury and Finance (DOTAF) play a co-ordinating role in government policy. Within DPAC, the Tasmania Together 2020 program, the Policy Division and the Social Inclusion Unit would all be expected to be areas with an interest in tobacco control. However, there was no indication that reducing smoking rates were ever a priority for DPAC. The Ten Year Review of Tasmania Together blandly notes that smoking reduction targets are unlikely to be achieved. [31] Yet a "will" to implement changes is fundamental for governments to achieve improvements in tobacco control.[32] A department with considerable influence over resource allocation was the Department of Treasury and Finance (DOTAF) but at no stage did Treasury publicly evince any concern at smoking rates in Tasmania. [S16] Mackenbach writes "Substantial health gains can be achieved if all countries would follow best practice, but this probably requires the removal of barriers related to both the 'will' and the 'means' to implement health policies." [32] A recent review reported "We encountered a deeply engrained culture of resistance to change and found this group was either unable or unwilling to set priorities."'[33] Cultural barriers such as a pervasive apathy and disinterest in tobacco control demonstrate that key Tasmanian government agencies acted as barriers.

Thirdly, within the DHHS itself there was indifference about tobacco control from key sections of the agency. [S26] Significantly, there was a prevailing belief in the senior decision-making ranks that mass media campaigns would not work to reduce smoking rates within low socio-economic status (SES) groups in Tasmania. Although completely contrary to international evidence, in March 2004 an influential senior official was reported to have said that the effectiveness of community education strategies "is overplayed". [S16] The fact that this particular key official did not support this approach meant that it would have been doomed at any discussion of budget initiatives. Davoudi writes that power determines what counts as knowledge, and power appears to have been overwhelmingly influential in this case. [34] The intrusion of the personal beliefs and values of powerful people into the bureaucratic process influenced the extent that evidence was believed. [35] Court and Young have written that research is more influential in policy making if it fits into the values and beliefs of the policy makers, is presented in such a way to be interesting to them, and there are shared networks, trust and good communication. "But these conditions are rarely met in practice." [36] This was certainly true in Tasmania.

\subsection{Influence of the Tobacco Industry}

The Tasmanian government has received services and money from a tobacco industry "front organisation", refused to provided details of meetings with the tobacco industry unless they were specifically requested under legislation, and said that it was not obliged to observe the provisions of the WHO Framework Convention on Tobacco Control. [37] The WHO condemns governmental association with tobacco industry front organisations. [38] The Acting Director of Public Health, on behalf of the Premier, in May 2009 said that the government considered Article 5.3 of the Convention; "...to be aimed more at improving transparency in third world countries rather than jurisdictions such as Tasmania where meetings with the tobacco industry are infrequent and [information is] obtainable under Freedom of Information." [S17] In 2009, one of Department of Primary Industry Parks, Water and Environment sub-agencies received $\$ 29,000$ from the Butt Littering Trust (BLT) and the Secretary of the Department naively explained in a briefing to the Environment Minister that the BLT although "...funding is largely donated by the tobacco industry, it operates as an independent entity." [S18] Tasmania has a history of crony capitalism and corruption in relation to dealings with the tobacco industry [39], and these examples indicate an inability to understand international obligations and the need to maintain distance from the tobacco industry in order to effectively implement tobacco-control reforms.

\subsection{Resource Constraints}

Funds within DHHS exist in separate specific "silos" and it has been perceived by staff as difficult to transfer unexpended funds from one area to another, or to access funding for new initiatives within the Population Health portfolio, as it has a very small budget compared to that for hospitals. There was very little discretionary funding available. [10] There was only one officer in the DHHS responsible for tobacco control policy and located in the Population Health Division. In 2006, a budget submission was prepared within the DHHS to address the question of pregnancy and smoking, but there was thought to be little likelihood of it being funded, despite known high smoking levels amongst pregnant women in Tasmania. This created concern, but there was no funding outcome. [S19] However, four positions were created in ADS in 2009 for nurses who were primarily concerned with clinical cessation services, but no additional funding for mass media campaigns until 2010 (Table 2). 
Table 2. Funding for Quit Tasmania (\$Aus-2010)

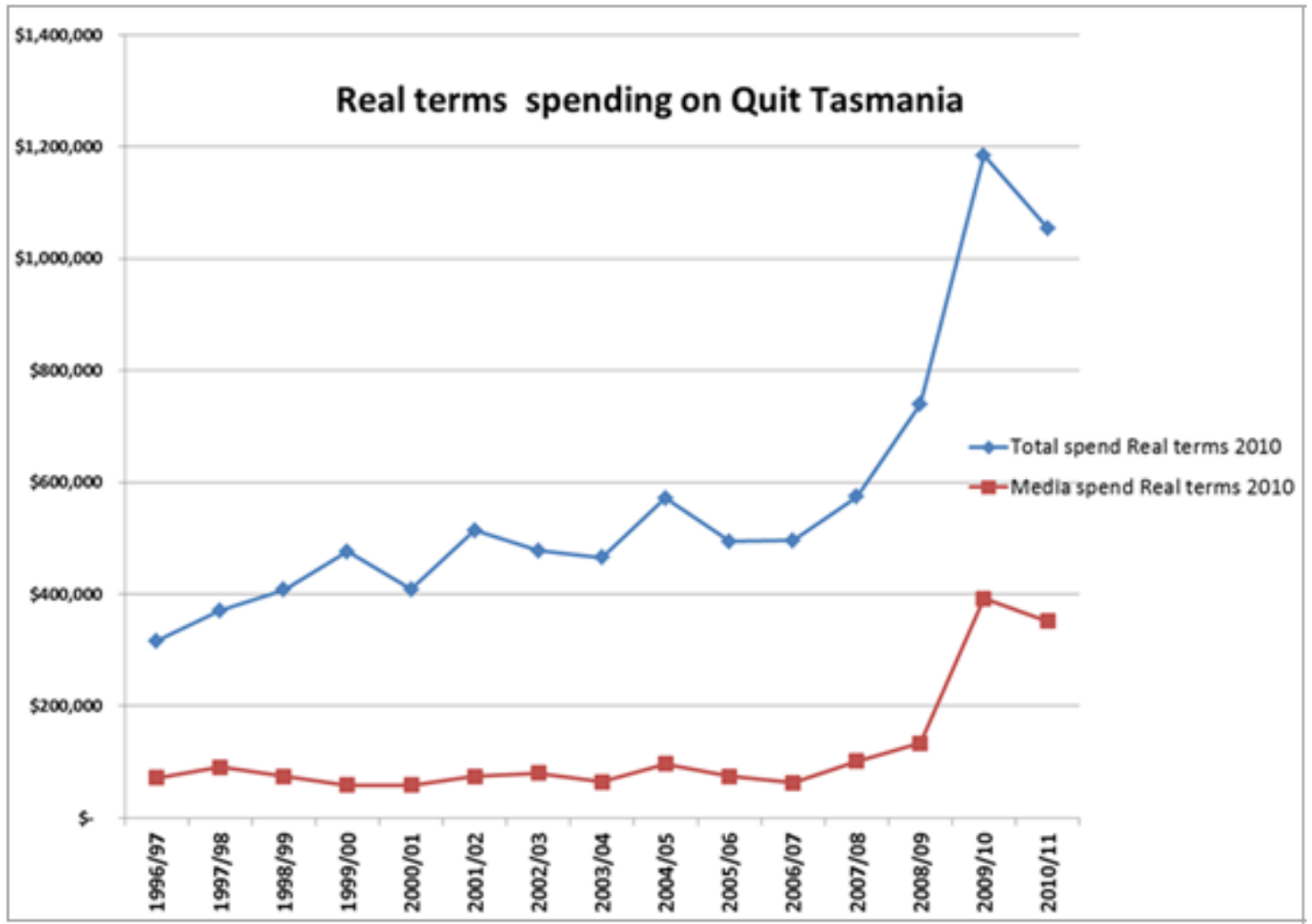

Source: Quit Tasmania

In a briefing to the Director of Population Health from the State Manager of the ADS, it was recommended that a review of Quit Tasmania (QT), the primary non-government smoking cessation organisation, be undertaken, and she said "...currently there are no surplus funds available....to allocate to Quit Tasmania."[S20] The ADS also expressed concern about whether they were getting value for money from the Tobacco Coalition, and that "...general concensus (sic) is that we do not address the problem well, the problems are fairly unique and complex. Certainly there is no coherent plan for managing the problem and nobody could identify a positive impact from the current investment." [S21]

Lack of funding was a definite constraint [S22] to deliver adequate programs and was a key barrier to effective tobacco control in Tasmania.

\subsection{Evaluation Delayed}

QT was not evaluated at all during the period from its establishment in 1995 until 2009, although the ADS recommended such in 2002 and 2005.There were continuing misgivings amongst bureaucrats about the operation of QT in the early 2000s, including concerns about it failing to fulfil its undertakings, some items of financial expenditure, failure to work effectively with the aboriginal community, and failure to undertake surveys. [S20] When the Review of QT was finally undertaken in 2009 very serious criticisms of the organisation emerged.[S23] Conducted by Professor Mike
Daube and the Public Health Advocacy Institute of Western Australia (PHAIWA), the review recommended sweeping changes to the Quit service, including significant restructuring, development of effective partnerships with other key organisations, restructuring of the Board, establishing a health promotion plan and a mass media program, cessation of delivery of extraneous non evidence-based services, revision of the strategic plan and redevelopment of the Quit website.

QT had also been reluctant to run effective media campaigns, for rather paradoxical and personal reasons. Meeting Minutes recorded, "...Quit Tasmania have not yet committed to running the campaign [because of] the negative public reaction given that the images are deliberately hard hitting. " [S23] The research evidence supports properly devised social marketing campaigns as being effective for low SES groups, although this group is difficult to engage. [40] The 2009 review of QT makes mention of the fact that the emphasis on clinical cessation support and Quit programs was a detriment to media campaigns. [S24] The Reviewers said "There is a lack of evidence based best practice across the range of services offered by Quit". Similar observations had been made in the earlier 2007 independent review of cessation services in Tasmania. Recommendations were made in both reports that additional funding was needed for mass media campaigns to trigger quit attempts. The effectiveness of media campaigns was acknowledged in internal government documents, but 
was not translated into action or commitment of funds.

The failure of QT to achieve a level of effectiveness was primarily the result of government ineptitude, not the workers within QT. [S23] Indeed members of the government Steering Committee (ATODS) in 2009 considered that the DHHS "...should take some responsibility for the findings of the report". [S25]

\section{Limitations}

For this study, government documents were made available to the author through the Right to Information Act 2009 and its predecessor Act. Some of these documents contained redacted sections, for example relating to the review of QT. Few ministerial briefings and no internal budget documents were provided. Many documents could not be coded because of their bulk or format but were sorted and analysed individually.

\section{Conclusions ${ }^{1}$}

The process of establishing tobacco control as a major priority in Tasmania, (1997-2010) was subverted by various forces operating within the government bureaucracy. The transfer of knowledge or evidence to senior decision makers, and parliament, was patchy and in some cases non-existent. Confused accountability and complex processes and excessive internal "consultation", contributed to policy proposals for action being "jammed up" and never reaching an outcome or an authoritative decision. Cultural barriers included a close relationship between governments and the tobacco industry, lack of "belief" in particular evidence-informed programs, primacy of the "rescue" culture, and passive and active obstruction from several key government agencies.

Reviews conducted by expert external consultants highlighted the potential and need for mass media campaigns in Tasmania, and made strong recommendations about necessary funding, but were not adequately implemented. Additional funding was provided, but allocated only to clinical services rather than more comprehensively including mass media campaigns, as recommended internationally. [17-23] The Evaluation of Quit Tasmania found many problems and commented (although it was outside the terms of reference) that Tasmania should "reduce funding for personalised smoking cessation activity and devote as much of this funding as possible to media programs". [S23] Again this was not implemented.

Structural impediments, inducing cumbersome decision

\footnotetext{
${ }^{1}$ Author's note: Since 2010 a number of changes have occurred including; increased funding from the federal government for mass media campaigns; changes in staffing at the Alcohol and Drug Service; restructure of Quit Tasmania and its merger with the Cancer Council Tasmania; acceptance that mass media campaigns are beneficial in reducing smoking rates; a change of government, and national drug strategy processes have been reformed.
}

making for evidence-based tobacco control, are not confined to Tasmania, or other states in Australia. Australian structures have also been identified as failing to deliver evidence-based tobacco control and "....... advisory structures have been explicitly and intentionally structured to filter the information inputs, .....(so).... research evidence receives less attention, in policy considerations, than it should." [15] The same impediment was found in local-level tobacco control in California. Satterlund found that the “...bureaucracy ..... as well as the lengthy decision-making processes, tended to slow down or hinder the policy campaigns of local projects." [42] Zeller identified similar issues within the US FDA. [28] But all of these impediments have certainly been very prominent in Tasmania and a catalogue of errors in public policy making characterised its tobacco control including failure to follow or transfer evidence; complex decision making structures, and government-wide indifference to reducing smoking rates. No advice was given to Parliament of effective measures; or appropriate priorities. Passive and active obstruction from some agencies, resource constraints and relationships with tobacco industry fronts, all contributed to this.

In the late 1990s and most of the 2000s there was a loss of focus in government on mass media campaigns as important for tobacco control in Tasmania. Individual bureaucrats worked to achieve sound results in legislative reforms and in later years in clinical cessation support services, but the "whole of government" commitment to funding for vital mass media campaigns remained absent. There was a set of cultural beliefs operating within the bureaucracy that mass media campaigns were inadequate to assist low SES groups, despite evidence to the contrary. There was also a lack of clarity on governmental roles and accountability on tobacco issues. There was a lack of discretionary funding within the responsible government Department which impeded initiatives. The final major impediment to implementation of a comprehensive evidence-based strategy in tobacco control in Tasmania was a lack of bureaucratic control, monitoring, evaluation and support for the principal service delivery arm of anti-smoking services, Quit Tasmania.

In summary, Tasmania continued to have disproportionately a high smoking rate that was not falling in the 2000s at the same rate as the rest of Australia. Whilst there were many legislative reforms, there was a failure to provide adequate resources for mass media cessation programs and educational campaigns from 1997 to 2009. Knowledge transfer about evidence-based programs from the bureaucracy to government and parliament and commitment to cessation support services did not occur until the late 2000s. These failings can be attributed to structural and process problems; a set of cultural beliefs that did not accord with the evidence; unclear accountability; indifference to tobacco control from the senior echelons of government; and a lack of resources, support, monitoring and evaluation of the major cessation anti-smoking services.

\section{Implications}


There are a number of actions that could be taken to ensure that Tasmania, and other jurisdictions, respond effectively to the smoking pandemic. Firstly, the cabinet should publicly endorse reducing smoking rates as a priority for the government, allocate significant additional funding, and may need to source additional funds from the federal government for this purpose, and gain genuine commitment from Ministers and Departments right across government. Secondly, elimination of iterative internal circular "over-consultation" processes that bog down decision making on tobacco control is essential; and policy processes either need to give equal weight to tobacco control or be structurally separated from illicit drugs and alcohol. Thirdly, small scale external evaluations and reviews of tobacco control programs should occur every two years. Included in this process should be the prioritisation of initiatives to achieve no more than three practical outcome-focussed measurable targets. These initiatives need to be fully funded and evaluated.

\section{Supplementary Information}

These include internal documents obtained from government departments under Tasmanian Right to Information (previously Freedom of Information) legislation, which are now public documents and may be quoted as such. Included are some graphs, a document supplied by ASH Australia. They may be obtained from the corresponding author, or the author's institution.

Supplementary References (Marked in text as S1-S26)

1. Inter Agency Working Group on Drugs. Terms of Reference, Department of Health and Human Services Tasmania,. Hobart: Department of Health and Human Services, Tasmania; 2004.

2. McDonald D. Email correspondence 2011.

3. Tobacco Coalition Minutes, 22 August 2006, Department of Health and Human Services. Hobart.

4. Global Public Health. Report on Smoking Cessation Review - Tasmania. Glenorchy, New Zealand: Department of Health and Human Services, Tasmania; September, 2007.

5. Department of Health and Human Services Tasmania. Tobacco Coalition Minutes, Hobart: 21 February 2006

6. Population Health. Investment in tobacco control 2009-2010. Department of Health and Human Services Tasmania, Hobart: Tasmania.

7. Department of Health and Human Services Tasmania website. http://www.dhhs.tas.gov.au/

8. Tasmanian Drug Strategy and IAWGD Governance Schema August 2010

9. Inter Agency working Group on Drugs. Minutes. Department of Health and Human Services Tasmania, Monday 1 September 2008.
10. Owen C, D'Silva N, Mckeown C. Email series Tobacco action plan final consultation process. Hobart: DHHS; 2003. p. 2.

11. Bent M, Brkic M, Ramsay JA. Minute to the minister: Ministerial no: 19865. Department of Health and Human Services Tasmania, Hobart: 11 December 2003.

12. Tobacco Coalition. Target 16, Implementation plan for the Tasmanian Tobacco Action Plan 2006-2010.. Version 4.2 July 2009 ed. Hobart: DHHS.

13. Acting Secretary Darren Hine. Submission to the Department of Health and Human Services. Management Department of Police and Emergency Services, Hobart: DHHS; 29 September 2010. . 2.

14. Tobacco Coalition. Tobacco Coalition minutes, April 2004, Hobart: DHHS; 2004.

15. ATOD Steering Minutes, Department of Health and Human Services Tasmania, Hobart: 2010.

16. Lypka B, Taylor R. et al IAPCC decisions, Email, Department of Health and Human Services Tasmania, Hobart: 18 March 2004.

17. Pickin C. Letter from the acting Director of Public Health on behalf of the Premier to ASH Australia. Department of Health and Human Services Tasmania, Hobart April 2009.

18. Gadd S. Extract from Departmental briefing to the Environment Minister. Hobart: Department of Environment; 8 April 2009.

19. Tobacco Coalition Minutes. Department of Health and Human Services Tasmania, Hobart; 1 March 2007

20. D'Silva N, McKeown C. Director briefing. Department of Health and Human Services Tasmania, Hobart: 2002.

21. Fjeldsoe K, Quinn W, Massina M, Engels S. Memo from Roscoe Taylor re: Continued funding for tobacco coalition position. Department of Health and Human Services Tasmania, Email series. Hobart: 30 March 2005.

22. Funding for Quit over time - graph attached

23. Tobacco Coalition Minutes. Department of Health and Human Services Tasmania, Hobart Tuesday October 252005.

24. Public Health Advocacy Institute of Western Australia. Evaluation and review of quit Tasmania; 2009.

25. ATOD Alcohol and Other Drug Service Review, Steering Committee Minutes. Department of Health and Human Services Tasmania, Hobart: 30 April 2009.

26. Frohmader, M, Tobacco Coalition. Email to W Quinn. Department of Health and Human Services, Hobart, Tuesday 25 October 200512.38 pm. 


\section{REFERENCES}

[1] Australian Bureau of Statistics. 4364do002 20112012 Australian Health Survey: Updated results, 2011-12. In: ABS, Canberra: Australian Bureau of Statistics; 7 June 2013.

[2] Taylor R. State of Public Health Report. Department of Health and Human Services Tasmania, Hobart: DHHS; 2013.

[3] DHHS submission to the Legislative Council Government Administration Committee, Inquiry into DHHS cost reduction strategies. Accessed 26 November 2014 http://www.parliament.tas.gov.au/ctee/council/Submissions/ Govt $\% 20$ Admin\%20A_Health_Submission\%20from\%20D HHS.pdf

[4] Professor Simon Foote, "A new Menzies on the horizon" Media Release, Menzies Institute for Medical Research, University of Tasmania, 5 June 2006 Accessed 26 November 2014

http://www.menzies.utas.edu.au/article.php?Doo=ContentVi ew\&id $=970$

[5] Ballard J. The Politics of Tobacco Control in Australia: International Template? In: Feldman EA, Bayer R, editors. Unfiltered: Conflicts over Tobacco Policy and Public Health. Cambridge Massachusetts: Harvard University Press; 2004. p. 104.

[6] Kingdon JW. Agendas, alternatives, and public policies. 2nd ed. New York: Longman; 1995.

[7] UCSF Library. A digital library of tobacco documents. Legacy Library 2013 Continuously updated [accessed 1 May 2013]; The Legacy Tobacco Documents Library (LTDL) contains more than 14 million documents $(80+$ million pages) created by major tobacco companies related to their advertising, manufacturing, marketing, sales, and scientific research activities.]. Available from: http://legacy.library.ucsf.edu/

[8] Parliament of Tasmania Hansard. [Website] 1992-2014 continuously updated. Record of Parliamentary proceedings. Available from: http://www.parliament.tas.gov.au/\#

[9] Cairney P, Studlar DT, Mamudu HM. Global Tobacco Control: Policy, Governance and Transfer,. New York: Palgrave MacMillan; 2012. Page 50

[10] Cairney P, Mamudu H. The global tobacco control "endgame": Change the policy environment to implement the FCTC. Journal of Public Health Policy 2014;35(4):506-17.

[11] Department of Health and Human Services Annual Report 2005-2006.Hobart; 2005-2006. http://www.dhhs.tas.gov.au/

[12] Blake HM. Hospital bed management and primary preventive health: Report of the auditor-general no.10 of 2012-13. In: Tasmanian Audit Office,. Hobart: Parliament of Tasmania; 2013. p. 70.

[13] Intergovernmental Committee on Drugs. Annual Report to the Ministerial Council on Drug Strategy 2009-2010. In: Department of Health and Ageing Drug Strategy Branch, Canberra: Department of Health and Ageing, Commonwealth of Australia; 2009-2010.

[14] Intergovernmental Committee on Drugs. Annual Report to the Ministerial Council on Drug Strategy 2008-2009. In: Department of Health and Ageing Drug Strategy Branch, Canberra: Department of Health and Ageing; 2008-2009.
[15] McDonald D. Australian governments' spending on preventing and responding to drug abuse should target the main sources of drug-related harm and the most cost-effective interventions. Drug and Alcohol Review. 2011;30(1):96-100.

[16] Anne Mather. 'Jackson labels Department 'a basket case'. Anti-drugs chief quits, Department of Health and Human Services. Hobart Mercury newspaper. February 8 2006, Page 1.

[17] Bala M, L S, Cahill K. Mass media interventions for smoking cessation in adults (review). The Cochrane Database of Systematic Reviews. 2008 January(1).

[18] Wakefield M, Chaloupka F. Effectiveness of comprehensive tobacco control programmes in reducing teenage smoking in the USA. Tobacco Control. 2000 June 1, 2000;9(2):177-186.

[19] Farrelly MC, Davis KC, Haviland ML, Messeri P, Healton CG. Evidence of a dose-response relationship between "truth" antismoking ads and youth smoking prevalence. American Journal of Public Health. 2005;95(3):425-31.

[20] Biener L, Reimer RL, Wakefield M, Szczypka G, Rigotti NA, Connolly G. Impact of smoking cessation aids and mass media among recent quitters. American Journal of Preventive Medicine. 2006;30(3):217-224.

[21] Wakefield MA, Durkin S, Spittal MJ, Siahpush M, Scollo M, Simpson JA, et al. Impact of tobacco control policies and mass media campaigns on monthly adult smoking prevalence. American Journal of Public Health. 2008;98(8):1443.

[22] Daube M. Forty years on - tobacco control then and now. Australian and New Zealand Journal of Public Health. 2013;37(4):303-304.

[23] Centers of Disease Control and Prevention (CDC). Best practices for comprehensive tobacco control programs. Atlanta: National Center for Chronic Disease Prevention and Health Promotion, Office on smoking and Health; October 2007. p. 1-122.

[24] Taylor Roscoe. State of Public Health Report. Department of Health and Human Services Tasmania, Hobart: DHHS; 2003. p. 26.

[25] Taylor R. State of Public Health Report. Department of Health and Human Services Tasmania, Tasmanian Government; 2008. p. 34.

[26] Siggins Miller. Evaluation and monitoring of the national drug strategy 2004-2009. Evaluation: Australian Government; 2009 April 2009.

[27] McDonald P, Viehbeck S, Robinson S, Leatherdale S, Nykiforuk C, Jolin MA. Building research capacity for evidence-informed tobacco control in Canada: A case description. Tobacco Induced Diseases. 2009;5(1):12.23

[28] Zeller M. Three years later: An assessment of the implementation of the family smoking prevention and tobacco control act. Tobacco Control. 2012 August 2, 2012.

[29] McGinnis JM. Does proof matter? Why strong evidence sometimes yields weak action. American Journal of Health Promotion. 2001;15(5):391-396.

[30] Isett KR. In and across bureaucracy: Structural and administrative issues for the tobacco endgame. Tobacco Control. 2013;22(Supplement 1):i58-i60. 
[31] Tasmania Together Progress Board. Tasmania Together Annual Report 2010-11. In: Department of Premier and Cabinet Tasmania, Hobart; 2011. p. 23.

[32] Mackenbach JP, McKee M. A comparative analysis of health policy performance in 43 European countries. The European Journal of Public Health. 2013;23(2):195-201.

[33] Bansemer A, Wellington H, MacDonald A. The Commission on Delivery of Health Services in Tasmania: working towards a sustainable health system for Tasmania, Commonwealth. Department of Health. Canberra. 2014: p46.

[34] Davoudi S. Evidence-based planning: Rhetoric and reality. The Planning Review. 201201 November 2012 42(165):14-24.

[35] McCaughey D, Bruning N. Rationality versus reality: The challenges of evidence-based decision making for health policy makers. Implementation Science. 2010;5(1):39.

[36] Court J, Young J. Bridging research and policy in international development: An analytical and practical framework. Development in Practice. 2006;16(1):85-90.

[37] World Health Organisation. WHO Framework Convention on Tobacco Control. World Health Organization, 2005 World Health Organisation; 2003. p. 8.
[38] Conference of the Parties, World Health Organisation. Guidelines for Implementation of Article 5.3 of the WHO Framework on Tobacco Control. Geneva: WHO; 2012. p. 13.

[39] Barnsley K. Crony capitalism or corruption? The curious case of British Tobacco and a Tasmanian Government, Tasmanian Historical Research Association. 2011 August 2011;58(2):173-182.

[40] Niederdeppe J, Kuang X, Crock B, Skelton A. Media campaigns to promote smoking cessation among socioeconomically disadvantaged populations: What do we know, what do we need to learn, and what should we do now? Social Science \& Medicine. 2008;67(9):1343-1355.

[41] Durkin SJ, Biener L, Wakefield MA. Effects of different types of antismoking ads on reducing disparities in smoking cessation among socioeconomic subgroups. American Journal of Public Health. 2009;99(12):2217.

[42] Satterlund TD, Cassady D, Treiber J, Lemp C. Barriers to adopting and implementing local-level tobacco control policies. Journal of Community Health. 201031 December 2010 . 